\title{
Impact of Antithrombotic Regimen on Mortality, Ischemic, and Bleeding Outcomes after Transcatheter Aortic Valve Replacement
}

\author{
Anubodh Varshney · Ryan A. Watson · Andrew Noll • \\ KyungAh Im · Jeffrey Rossi · Pinak Shah · Robert P. Giugliano
}

Received: March 30, 2018 / Published online: May 19, 2018

(C) The Author(s) 2018

\section{ABSTRACT}

Introduction: Optimal antithrombotic therapy after transcatheter aortic valve replacement (TAVR) remains unclear. We evaluated the association between antithrombotic regimens and outcomes in TAVR patients.

Methods: We retrospectively analyzed consecutive patients who underwent TAVR at a single academic center from April 2009 to March

Enhanced digital features To view enhanced digital features for this article, go to https://doi.org/10.6084/ m9.figshare.6205685.

A. Varshney

Brigham and Women's Hospital Department of Medicine and Harvard Medical School, Boston, MA, USA

R. A. Watson

Department of Medicine, Division of Cardiology, Thomas Jefferson University Hospital, Philadelphia, USA

A. Noll · J. Rossi

Department of Cardiovascular Medicine, Cleveland Clinic, Cleveland, $\mathrm{OH}$, USA

K. Im · R. P. Giugliano ( $₫)$

Thrombolysis in Myocardial Infarction (TIMI) Study Group, Brigham and Women's Hospital, Harvard

Medical School, Boston, MA, USA

e-mail: rgiugliano@partners.org

P. Shah · R. P. Giugliano

Brigham and Women's Hospital Heart and Vascular Center and Harvard Medical School, Boston, MA, USA
2014. Antithrombotic regimens were classified as single or dual antiplatelet therapy (AP), single antiplatelet plus anticoagulant (SAC), or triple therapy (TT). The primary endpoint was a composite of death, myocardial infarction (MI), stroke, and major bleeding. Adjusted hazard ratios (HRs) were obtained with best subset variable selection methods using bootstrap resampling.

Results: Of 246 patients who underwent TAVR, 241 were eligible for analysis with 133, 88, and 20 patients in the AP, SAC, and TT groups, respectively. During a median 2.1-year followup, $53.5 \%$ had at least one endpoint - the most common was death $(68 \%)$, followed by major bleeding (23\%), stroke (6\%), and MI (3\%). At 2 years, the composite outcome occurred in $70 \%$ of TT, $42 \%$ of SAC, and $31 \%$ of AP patients. Compared to AP, adjusted HRs for the composite outcome were 2.88 [95\% Confidence intervals (CI) (1.61-5.16); $p=0.0004]$ and 1.66 (95\% CI $[1.13-2.42] ; p=0.009)$ in the TT and SAC groups, respectively. Mortality rates at 2 years were $61 \%$ in the TT, $32 \%$ in the SAC, and $26 \%$ in the AP groups ( $p=0.005)$.

Conclusions: The risk of the composite outcome of death, MI, stroke, or major bleeding at 2-year follow-up was significantly higher in TAVR patients treated with TT or SAC versus AP, even after multivariate adjustment.

Keywords: Antithrombosis; Aortic stenosis; Transcatheter aortic valve replacement 


\section{INTRODUCTION}

Transcatheter aortic valve replacement (TAVR) has become an established treatment for patients with symptomatic, severe aortic stenosis with intermediate, high, or prohibitive surgical risk [1-5]. Despite advances in patient selection, operator experience, and valve delivery systems, ischemic and bleeding complications remain important concerns after TAVR, as they are associated with increased morbidity and mortality [6-8]. However, limited data are available comparing long-term outcomes with varying antithrombotic regimens after TAVR.

Current guidelines recommend dual antiplatelet therapy with aspirin (indefinitely) and clopidogrel (for 1-6 months) after TAVR in patients with no indication for therapeutic oral anticoagulation (OAC). In patients with an indication for OAC, guidelines generally recommend against the use of triple therapy [9-12]. However, these recommendations have been made empirically and vary amongst professional societies, leading to heterogeneity in clinical practice [13].

We sought to examine the association between different antithrombotic regimens and the risk of mortality, ischemic, and bleeding outcomes in a non-selected clinical population undergoing TAVR. Specifically, we compared outcomes among TAVR patients prescribed single or dual antiplatelet therapy (AP), a single antiplatelet agent plus OAC (SAC), or triple therapy (TT) with dual antiplatelet therapy (DAPT) and OAC.

\section{METHODS}

\section{Study Population}

We retrospectively analyzed consecutive patients who underwent TAVR at Brigham and Women's Hospital in Boston, Massachusetts, from April 2009 through March 2014. Baseline medical history, routine laboratory testing, electrocardiography, echocardiography, CHA2DS2-VASc score, ATRIA score, New York Heart Association functional classification, preprocedure antithrombotic regimen, and TAVR procedural characteristics were collected. Patients were then prospectively followed for ascertainment of study outcomes. The Institutional Review Board of Partners Healthcare in Boston, Massachusetts, approved the study, and signed informed consent was obtained from each patient. All procedures performed in studies involving human participants were in accordance with the 1964 Helsinki Declaration and its later amendments or comparable ethical standards.

\section{Antithrombotic Regimen}

The antithrombotic regimen was noted preTAVR, at the time of discharge from TAVR admission, at 30 days, at 1 year, and through April 2016 using electronic health records and telephone follow-up. Antithrombotic regimens were classified as single or dual antiplatelet therapy only (AP), single antiplatelet plus anticoagulant therapy (SAC), or triple therapy (TT) with DAPT plus OAC. Patients were grouped according to the antithrombotic regimen at the time of latest follow-up for the purposes of the statistical analysis.

\section{Outcomes}

The primary endpoint was the composite of death, myocardial infarction (MI), stroke, or major bleeding (requiring hospitalization, lifethreatening, or fatal). Outcomes were assessed according to Valve Academic Research Consortium-2 definitions [14] at discharge, 30 days, 1 year, and through April 2016 using electronic medical record data and telephone follow-up with a standardized questionnaire.

\section{Statistical Analysis}

To determine associations between antithrombotic therapy group and the primary composite outcome, a Cox proportional hazards model was used. A multivariable model was developed with best subset variable selection methods using bootstrap resampling in order to account for model variation due to small sample size [15]. The final model included adjustment for 
chronic lung disease, prior percutaneous coronary intervention (PCI), male sex, age, and lowgradient aortic stenosis (defined as left ventricular ejection fraction $<50 \%$, aortic valve area $<1.0 \mathrm{~cm}^{2}$, and mean aortic valve gradient $<40 \mathrm{mmHg}$ ). Results are reported as adjusted hazard ratios (HR) and 95\% confidence intervals (CI). Proportional hazards assumption for the final model was assessed by score tests using scaled Schoenfeld residuals. Crude cumulative event rates were calculated by the complement of Kaplan-Meier survival estimates, and log-rank test $p$ values are also reported. All reported $p$ values are two-sided, and significance level was set at alpha 0.05. Analyses were performed using SAS version 9.4 (SAS Institute Inc., Cary, NC, USA).

\section{RESULTS}

Table 1 outlines the baseline characteristics of each study group. A total of 246 patients underwent TAVR from April 2009 to March 2014. Of these, five patients were excluded for the following reasons: prescribed no antithrombotic therapy $(n=2)$ and incomplete post-discharge follow-up $(n=3)$, leaving 241 patients for final analysis. The baseline characteristics among the AP $(n=133)$, SAC $(n=88)$, and TT $(n=20)$ groups were similar, with the exception of rates of atrial fibrillation or flutter $(p<0.01)$, indication for OAC $(p<0.01)$, aortic valve mean gradient $(p=0.044)$, and aortic valve peak velocity $(p=0.047)$ (Table 1$)$. Overall, $67.2 \%$ of cases were done with a transfemoral approach, while $16.2 \%$ and $15.8 \%$ of cases were performed via a transapical and transaortic approach, respectively.

Of the 241 patients followed for a median of 2.1 years (interquartile range, 0.7-2.9 years), $53.5 \%(n=129)$ had at least one endpoint. The components of the composite outcome in the cohort were distributed as death $(68 \%)$, major bleeding (23\%), stroke (6\%), and MI (3\%) at 2-year follow-up. The risk of the composite outcome was highest with TT (70\%; HR 2.88, 95\% CI 1.61-5.16, $p=0.0004)$ and intermediate with SAC (42\%; HR 1.66, 95\% CI 1.13-2.42, $p=0.009)$, compared to AP $(31 \%)$ at 2 years
(Fig. 1). Mortality rates at 2 years were $61 \%$, $32 \%$, and $26 \%(p=0.005)$ in the TT, SAC, and AP groups, respectively, while major bleeding rates were $29 \%, 18 \%$, and $9.1 \%$, respectively $(p=0.02)$. Rates of stroke and MI were low and similar among groups.

A total of 132 patients in the cohort had an indication for OAC $(88.6 \%$ had atrial fibrillation or flutter), including 40 in the AP group, 76 in the SAC group, and 16 in the TT group. Among patients with an indication for OAC, the composite outcome occurred in $69 \%$ of TT, $38 \%$ of SAC, and $38 \%$ of AP patients $(p=0.06)$ at 2 -year follow-up.

\section{DISCUSSION}

This study evaluated the association between post-TAVR antithrombotic regimen and the composite outcome of death, MI, stroke, or major bleeding in a single-center cohort of 241 consecutive patients with at least 2-year followup. Patients treated with TT or SAC versus AP had a higher incidence of the composite outcome, even after multivariate adjustment. This finding was driven by an increase in both mortality and major bleeding in the TT and SAC groups.

TAVR patients are at high risk for both ischemic and bleeding events by virtue of comorbidities and the procedure itself. Both types of complications are associated with increased morbidity and mortality. Moreover, TAVR patients frequently undergo pre-emptive coronary artery stenting, which necessitates DAPT, and approximately half have atrial fibrillation requiring OAC. Given this complex interplay, identifying an antithrombotic regimen that achieves an optimal balance between ischemic protection and bleeding risk mitigation is paramount in this patient population. Nevertheless, guideline recommendations for antithrombotic therapy after TAVR remain empiric, and are extrapolated from the PCI experience and early TAVR clinical trial protocols [16].

Our analysis indicates that treatment with TT or SAC is associated with adverse clinical outcomes compared to treatment with AP alone 
Table 1 Patient characteristics by study group

\begin{tabular}{|c|c|c|c|c|c|}
\hline & $\mathrm{AP}(n=133)$ & SAC $(n=88)$ & TT $(n=20)$ & Overall $(n=241)$ & $p$ value \\
\hline Age (years) & $80.9 \pm 10.0$ & $81.0 \pm 7.9$ & $80.9 \pm 6.3$ & $80.9 \pm 9.0$ & 0.68 \\
\hline Male sex, $n(\%)$ & $63(47.4)$ & $53(60.2)$ & $12(60)$ & $128(53.1)$ & 0.14 \\
\hline $\operatorname{BMI}\left(\mathrm{kg} / \mathrm{m}^{2}\right)$ & $26.6 \pm 7.4$ & $28.2 \pm 5.9$ & $28.1 \pm 5.3$ & $27.3 \pm 6.8$ & 0.053 \\
\hline Atrial fibrillation or flutter, $n(\%)$ & $31(23.3)$ & $72(81.8)$ & $14(70)$ & $117(48.5)$ & $<0.001$ \\
\hline Prior DVT/PE, $n(\%)$ & $9(6.8)$ & $11(12.5)$ & $2(10)$ & $22(9.1)$ & 0.35 \\
\hline CHA2DS2-VASc score & $5.2 \pm 1.3$ & $5.5 \pm 1.2$ & $5.7 \pm 1.1$ & $5.4 \pm 1.3$ & 0.10 \\
\hline ATRIA score & $2.7 \pm 1.0$ & $2.7 \pm 0.8$ & $3.1 \pm 0.8$ & $2.7 \pm 0.9$ & 0.20 \\
\hline Indication for OAC, $n(\%)$ & $40(30.1)$ & $76(86.4)$ & $16(80)$ & $132(54.8)$ & $<0.001$ \\
\hline Prior GI bleeding, $n(\%)$ & $23(17.3)$ & $9(10.2)$ & $4(20)$ & $36(14.9)$ & 0.28 \\
\hline Dyslipidemia, $n$ (\%) & $105(78.9)$ & $72(81.8)$ & $20(100)$ & $197(81.7)$ & 0.076 \\
\hline Hypertension, $n$ (\%) & $117(88)$ & $81(92)$ & $20(100)$ & $218(90.5)$ & 0.19 \\
\hline Diabetes mellitus, $n$ (\%) & $52(39.1)$ & $37(42)$ & $7(35)$ & $96(39.8)$ & 0.82 \\
\hline Prior PCI, $n(\%)$ & $37(27.8)$ & $25(28.4)$ & $9(45)$ & $71(29.5)$ & 0.28 \\
\hline Peripheral arterial disease, $n(\%)$ & $30(22.6)$ & $19(21.6)$ & $6(30)$ & $55(22.8)$ & 0.72 \\
\hline Cerebrovascular disease, $n(\%)$ & $14(10.5)$ & $16(18.2)$ & $4(20)$ & $34(14.1)$ & 0.20 \\
\hline Chronic lung disease, $n$ (\%) & $49(36.8)$ & $41(46.6)$ & $8(40)$ & $98(40.7)$ & 0.35 \\
\hline On hemodialysis, $n(\%)$ & $5(3.8)$ & $2(2.3)$ & $1(5)$ & $8(3.3)$ & 0.76 \\
\hline NYHA class, $n(\%)$ & & & & & 0.86 \\
\hline I & $0(0)$ & $1(1.2)$ & $0(0)$ & $1(0.4)$ & \\
\hline II & $7(5.7)$ & $5(5.9)$ & $2(10.5)$ & $14(6.2)$ & \\
\hline III & $82(66.7)$ & $55(64.7)$ & $11(57.9)$ & $148(65.2)$ & \\
\hline IV & $34(27.6)$ & $24(28.2)$ & $6(31.6)$ & $64(28.2)$ & \\
\hline LVEF (\%) & $52.9 \pm 15.0$ & $54.4 \pm 14.2$ & $55.3 \pm 16.8$ & $53.7 \pm 14.8$ & 0.60 \\
\hline Aortic valve area $\left(\mathrm{cm}^{2}\right)$ & $0.6 \pm 0.2$ & $0.7 \pm 0.2$ & $0.7 \pm 0.1$ & $0.7 \pm 0.2$ & 0.65 \\
\hline Aortic valve mean gradient $(\mathrm{mmHg})$ & $47.0 \pm 13.8$ & $41.7 \pm 12.3$ & $43.1 \pm 15.6$ & $44.8 \pm 13.6$ & 0.045 \\
\hline Aortic valve peak velocity $(\mathrm{m} / \mathrm{s})$ & $4.4 \pm 0.6$ & $4.2 \pm 0.6$ & $4.3 \pm 0.8$ & $4.3 \pm 0.6$ & 0.047 \\
\hline Low gradient $\mathrm{AS}^{\mathrm{a}}, n(\%)$ & $24(18)$ & $11(12.5)$ & $2(10)$ & $37(15.4)$ & 0.42 \\
\hline Moderate or severe MR, $n(\%)$ & $47(38.5)$ & $33(38.4)$ & $7(36.8)$ & $87(38.3)$ & 0.99 \\
\hline Valve sheath access site $n(\%)$ & & & & & 0.41 \\
\hline Transfemoral & $93(69.9)$ & $56(63.6)$ & $13(65)$ & $162(67.2)$ & \\
\hline Transapical & $15(11.3)$ & $20(22.7)$ & $4(20)$ & $39(16.2)$ & \\
\hline Transaortic & $24(18)$ & $11(12.5)$ & $3(15)$ & $38(15.8)$ & \\
\hline
\end{tabular}


Table 1 continued

\begin{tabular}{|c|c|c|c|c|c|}
\hline & AP $(n=133)$ & SAC $(n=88)$ & TT $(n=20)$ & Overall $(n=241)$ & $p$ value \\
\hline Other & $1(0.8)$ & $1(1.1)$ & $0(0)$ & $2(0.8)$ & \\
\hline
\end{tabular}

Continuous variables are presented as mean \pm standard deviation

$A P$ antiplatelet therapy, $S A C$ single antiplatelet plus oral anticoagulant therapy, $T T$ triple therapy, $B M I$ body mass index, $D V T$ deep venous thrombosis, $P E$ pulmonary embolism, $A T R I A$ anticoagulation and risk factors in atrial fibrillation, $O A C$ oral anticoagulation, GI gastrointestinal, $P C I$ percutaneous coronary intervention, $N Y H A$ New York Heart Association, $L V E F$ left ventricular ejection fraction, $A S$ aortic stenosis, $M R$ mitral regurgitation

${ }^{a}$ Defined as aortic valve mean gradient $<40 \mathrm{mmHg}$, left ventricular ejection fraction $<50 \%$, and aortic valve area $<1 \mathrm{~cm}^{2}$

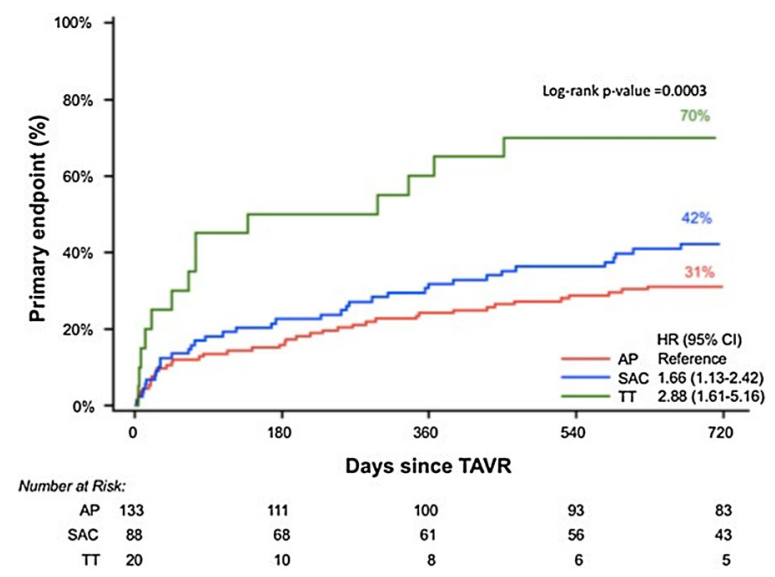

Fig. 1 Kaplan-Meier time-to-event curves for the primary composite endpoint of death, myocardial infarction, stroke, or major bleeding stratified by treatment group. $T A V R$ transcatheter aortic valve replacement, $H R$ hazard ratio, $C I$ confidence interval, $A P$ antiplatelet therapy, $S A C$ single antiplatelet plus anticoagulant therapy, $T T$ triple therapy

after TAVR, which is consistent with findings from other studies of patients undergoing TAVR $[17,18]$ and surgical aortic valve replacement [19]. We did not observe a benefit on ischemic endpoints with regimens using 2 or 3 antithrombotics compared to AP alone, as rates of MI and stroke were similar among the three treatment groups, but the study was not powered to do so. In addition to higher rates of bleeding with TT and SAC, we observed a higher mortality rate with these treatment strategies compared to AP. Importantly, our analysis shows that these effects persisted over a period of 2 years. However, while bleeding is reduced when fewer antithrombotic agents are used, omitting an anticoagulant in patients with atrial fibrillation (or another indication for OAC) significantly increases the risk of thromboembolism, which often has more serious clinical consequences than bleeding.

The relatively low number of patients, especially in the TT group, is an important limitation of our study. Additionally, patients in the TT and SAC groups had higher rates of atrial fibrillation/flutter and an indication for OAC, which could have led to confounding by indication despite our use bootstrap resampling. Patients were categorized based on antithrombotic regimen at the latest time of follow-up, and results could differ if an intention-to-treat analysis was carried out. The patients we studied represent a high-risk cohort, as evidenced by the large burden of co-morbidities and high 2 -year mortality rate. Thus, our results may not be applicable to lower-risk patients. Lastly, our study is observational in nature, and randomized trials are needed to determine the optimal antithrombotic regimen after TAVR in patients with and without an indication for anticoagulation. The recently reported aspirin versus aspirin + clopidogrel following transcatheter aortic valve implantation (ARTE) trial demonstrated that aspirin monotherapy reduced risk of bleeding, without increasing the risk of MI or stroke, compared to DAPT in TAVR patients [20]. Ongoing trials include ATLANTIS (NCT02664649), AUREA (NCT01642134), AVATAR (NCT02735902), ENVISAGE-TAVR (NCT02943785), GALILEO (NCT02556203), POPular-TAVI (NCT02247128), and TICTAVR (NCT02817789). The results of these trials will 
likely inform future guidelines and clinical decision-making.

\section{CONCLUSIONS}

In a consecutive series of patients from our institution undergoing TAVR between 2009 and 2014 , treatment with triple therapy or a single antiplatelet agent plus an oral anticoagulant was associated with an increased risk of the composite of death, MI, stroke, or major bleeding at 2 years compared to treatment with antiplatelet therapy alone, even after multivariable adjustment. Further prospective investigations to determine the optimal antithrombotic regimen in TAVR patients are awaited.

\section{ACKNOWLEDGEMENTS}

We thank the participants of the study.

Funding. No funding or sponsorship was received for this study or publication of this article.

Authorship. All named authors meet the International Committee of Medical Journal Editors (ICMJE) criteria for authorship for this article, take responsibility for the integrity of the work as a whole, and have given their approval for this version to be published.

Disclosures. Robert P. Giugliano reports research grant support from Daiichi Sankyo and Merck to his institution, and honoraria for CME programs and/or consultancy from Boehringer Ingelheim, Bristol Myers Squibb, Daiichi Sankyo, Merck, Pfizer, Portola, and Servier. Anubodh Varshney, Ryan A. Watson, Andrew Noll, KyungAh Im, Jeffrey Rossi and Pinak Shah have nothing to disclose.

Compliance with Ethics Guidelines. All procedures performed in this study were in accordance with the ethical standards of the Institutional Review Board of Partners Healthcare in Boston, Massachusetts and with the
1964 Helsinki declaration and its later amendments or comparable ethical standards. Informed consent was obtained from all individual participants included in the study.

Data Availability. The datasets during and/ or analyzed during the current study are available from the corresponding author on reasonable request.

Open Access. This article is distributed under the terms of the Creative Commons Attribution-NonCommercial 4.0 International License (http://creativecommons.org/licenses/ by-nc/4.0/), which permits any noncommercial use, distribution, and reproduction in any medium, provided you give appropriate credit to the original author(s) and the source, provide a link to the Creative Commons license, and indicate if changes were made.

\section{REFERENCES}

1. Leon MB, Smith CR, Mack M, Miller DC, Moses JW, Svensson LG, et al. Transcatheter aortic-valve implantation for aortic stenosis in patients who cannot undergo surgery. $\mathrm{N}$ Engl $\mathrm{J}$ Med. 2010;363:1597-607.

2. Smith CR, Leon MB, Mack MJ, Miller DC, Moses JW, Svensson LG, et al. Transcatheter versus surgical aortic-valve replacement in high-risk patients. N Engl J Med. 2011;364:2187-98.

3. Adams DH, Popma JJ, Reardon MJ, Yakubov SJ, Coselli JS, Deeb GM, et al. Transcatheter aorticvalve replacement with a self-expanding prosthesis. N Engl J Med. 2014;370:1790-8.

4. Leon MB, Smith CR, Mack MJ, Makkar RR, Svensson LG, Kodali SK, et al. Transcatheter or surgical aorticvalve replacement in intermediate-risk patients. N Engl J Med. 2016;374:1609-20.

5. Reardon MJ, Van Mieghem NM, Popma JJ, Kleiman NS, Søndergaard L, Mumtaz M, et al. Surgical or transcatheter aortic-valve replacement in intermediate-risk patients. N Engl J Med. 2017;376:1321-31.

6. Eggebrecht $H$, Schmermund A, Voigtländer $T$, Kahlert P, Erbel R, Mehta RH. Risk of stroke after transcatheter aortic valve implantation (TAVI): a meta-analysis of 10,037 published patients. EuroIntervention. 2012;8:129-38. 
7. Généreux P, Cohen DJ, Mack M, Rodes-Cabau J, Yadav $\mathrm{M}, \mathrm{Xu} \mathrm{K}$, et al. Incidence, predictors, and prognostic impact of late bleeding complications after transcatheter aortic valve replacement. J Am Coll Cardiol. 2014;64:2605-15.

8. Khatri PJ, Webb JG, Rodés-Cabau J, Fremes SE, Ruel M, Lau K, et al. Adverse effects associated with transcatheter aortic valve implantation: a metaanalysis of contemporary studies. Ann Intern Med. 2013;158:35-46.

9. Nishimura RA, Otto CM, Bonow RO, Carabello BA, Erwin JP, Guyton RA, et al. 2014 AHA/ACC guideline for the management of patients with valvular heart disease: a report of the American College of Cardiology/American Heart Association Task Force on Practice Guidelines. J Am Coll Cardiol. 2014;63:e57-185.

10. Joint Task Force on the Management of Valvular Heart Disease of the European Society of Cardiology (ESC), European Association for Cardio-Thoracic Surgery (EACTS), Vahanian A, Alfieri O, Andreotti F, Antunes MJ, et al. Guidelines on the management of valvular heart disease (version 2012). Eur Heart J. 2012;33:2451-96.

11. Webb J, Rodés-Cabau J, Fremes S, Pibarot P, Ruel M, Ibrahim $\mathrm{R}$, et al. Transcatheter aortic valve implantation: a Canadian Cardiovascular Society position statement. Can J Cardiol. 2012;28:520-8.

12. Holmes DR, Mack MJ, Kaul S, Agnihotri A, Alexander KP, Bailey SR, et al. 2012 ACCF/AATS/ SCAI/STS expert consensus document on transcatheter aortic valve replacement. J Am Coll Cardiol. 2012;59:1200-54.

13. Rossi JE, Noll A, Bergmark B, McCabe JM, Nemer D, Okada DR, et al. Variability in antithrombotic therapy regimens peri-TAVR: a single academic center experience. Cardiol Ther. 2015;4:197-201.
14. Kappetein AP, Head SJ, Généreux P, Piazza N, van Mieghem NM, Blackstone EH, et al. Updated standardized endpoint definitions for transcatheter aortic valve implantation: the Valve Academic Research Consortium-2 consensus document. J Am Coll Cardiol. 2012;60:1438-54.

15. Austin PC, Tu JV. Bootstrap methods for developing predictive models. Am Stat. 2004;58:131-7.

16. Carnicelli AP, O'Gara PT, Giugliano RP. Anticoagulation after heart valve replacement or transcatheter valve implantation. Am J Cardiol. 2016;118:1419-26.

17. Abdul-Jawad Altisent O, Durand E, Muñoz-García AJ, Nombela-Franco L, Cheema A, Kefer J, et al. Warfarin and antiplatelet therapy versus warfarin alone for treating patients with atrial fibrillation undergoing transcatheter aortic valve replacement. JACC Cardiovasc Interv. 2016;9:1706-17.

18. Stanger DE, Abdulla AH, Wong FT, Alipour S, Bressler BL, Wood DA, et al. Upper gastrointestinal bleeding following transcatheter aortic valve replacement: a retrospective analysis. Cathet Cardiovasc Interv. 2017;90:E53-61.

19. Riaz H, Alansari SAR, Khan MS, Riaz T, Raza S, Luni FK, et al. Safety and use of anticoagulation after aortic valve replacement with bioprostheses: a meta-analysis. Circ Cardiovasc Qual Outcomes. 2016;9:294-302.

20. Rodés-Cabau J, Masson J-B, Welsh RC, Garcia Del Blanco B, Pelletier M, Webb JG, et al. Aspirin versus aspirin plus clopidogrel as antithrombotic treatment following transcatheter aortic valve replacement with a balloon-expandable valve: the ARTE (aspirin versus aspirin + clopidogrel following transcatheter aortic valve implantation) randomized clinical trial. JACC Cardiovasc Interv. 2017;10:1357-65. 